\title{
Uses of Smart Phones Application on Physical Therapy for Pediatric Evaluation: Systematic Review
}

\author{
SARA M.M. KORTAM, M.Sc.; ZIENAB A. HUSSEIN, Ph.D. and SHIMAA M. REFAAT, Ph.D. \\ The Department of Physical Therapy for Pediatrics, Faculty of Physical Therapy, Cairo University
}

\begin{abstract}
Background: Rapid developments in technology have encouraged the use of smartphones in pediatric evaluation research and practice. Although many applications (apps) relating to physical activity are available from major smartphone platforms, relatively few have been tested in research studies to determine their effectiveness in evaluation of children strength and muscle power.
\end{abstract}

Aim of Study: The aim of the study to evaluate intra-rater reliability of smart phone application in measuring range of motion among normal children.

Material and Methods: In this article, we summarize data on use of smartphone apps for estimating range of motion based upon bibliographic searches with relevant search terms in PubMed and Google scholar.

Results: After screening the abstracts or full texts of articles, 20 eligible studies of the acceptability or efficacy of smartphone apps for increasing physical activity were identified. Of the 20 included studies, 9 were comparative research studies, 8 were reliability studies and 2 was across sectional studies. The results indicate that smartphone appscan be efficacious in pediatric evaluation although the magnitude of the intervention effectis modest. Participants of various ages and genders respond favorably to apps that automaticallytrack range of motion, track progress toward evaluation goals, and areuser-friendly and flexible enough for use with several types of range of motion.

Conclusions: In conclusion, Dr Goniometer smart phone application can be used in clinical practice and research as an easy and convenient alternative to a digital and universal goniometer.

Key Words: Smartphone applications - Physical activity Randomized controlled trials - Pediatric evaluation.

Correspondence to: Dr. Sara M.M. Kortam, The Department of Physical Therapy for Pediatrics, Faculty of Physical Therapy, Cairo University

\section{Introduction}

AN accurate and reliable measurement of the Range of Motion (ROM) is fundamental in the physical examination and functional evaluation different joints, as well as in the monitoring and evaluation of training or rehabilitation programs [1]. Range of motion is a key measurement to help in detecting and diagnosing musculoskeletal deficits, monitoring treatment progression, and guiding the treatment plan [2]. ROM has traditionally been assessed using visual estimation or long-arm goniometry (universal and digital goniometers) [3,4]. Recently, high-speed cinematography, or radiographic measurements have been established as the most accurate method of evaluating ROM $[\mathbf{5 , 6 ]}$. The digital or Electro Goniometer (EGM) seems to be effective to simplify the physical therapists' work in the functional evaluation of different joints because it can be held by only one hand and other hand free to stabilize a body part during measurements [5-7]. It has very good interrater and interrater reliability as universal goniometer with no statistical difference between them [8]. With the use of applications that can be downloaded onto the smartphone, these measurements can be transformed into meaningful assessment data such as joint range of motion [9]. One of the clear benefits of Smartphone photographybased goniometry over other devices is that it represents a portable tool accessible to all, its noninvasive nature and its cost-effectiveness for investigators and clinicians make it a practical tool to assist with evaluation and treatment compliance [10]. Using of app technology in children and adolescents is limited so there is a need continues to exist for validation studies on Dr. Goniometer app focused on goniometric measurement. So the aim of the current study was to evaluate the validity and the intra-rater of Dr. Goniometer for joint angle 
measurement at the elbow and knee, comparing it with that of that commonly used by digital goniometer in adolescents. Rapidtechnological advances have led to the emergence of smartphones that combine the voiceand text messaging functions of cell phones with powerful computing technology that can support third-party applications, internet access, and wireless connectivity with other devices [11]. In this article, we review published studies on the acceptability and efficacy of smartphone apps designed to estimate range of motion. Of particular interest were randomized control trials of the efficacy of smartphone apps in range of motion measurements in children. We also examined the results of qualitative studies.

\section{Material and Methods}

This study was conducted from January 2019 up to March 2020 after approval from different school. This review is based upon bibliographic searches in PubMed, Science Direct and Google scholar with relevant search terms. Articles published in English through Novembe2015 were identified using the following MeSH search terms and Boolean algebra commands: (Smartphones) and (range of motion) or (goniometery) or (elbow joint). The searches were not limited to words appearing in the title of an article. Studies that focused on patients withsignificant musculoskeletal pathology or pain, and anthropometric variation that would preclude joint range of motion measurement were excluded. Information obtained from bibliographic searchers (title and topic of article, information in abstract, geographic locality of a study, and key words) was used to determine whether to retain each article identified in this way. In addition, we identified reviews included in Cochrane reviews (http://community.cochrane.org/ cochrane-reviews) and published review articles and reviewed their references $[12,13]$. A total of 510 articles were identified in the PubMed bibliographic search; 71 articles were identified in the CINAHL bibliographic search. After screening the abstracts or full texts of these articles, 20 eligible studies of the acceptability or efficacy of smartphone apps for estimating range of motion were identified of the 20 included studies, 9 were comparative research studies, 8 were reliabily studies, and two was across sectional study. Information was obtained from each published article about characteristics of the study population, outcomes of interest, and findings including effect measures. Information was also obtained about the operating system, platform, device, manufacturer, and app version. According to Ozdalga et al., we defined the smartphone as any cellular device that has additional functions including a camera, Global Positioning System (GPS), and Wi-Fi capabilities and is running one of the following mobile devices: iPhone, Android, BlackBerry, or Windows Mobile [14]. We conducted a bibliographic search through Pubmed, Ovid and Scopus using the following keywords: Smartphone application range of motioniPhone-Dr. Goniometer-"Android phone"-"Windows Mobile phone" research results were analyzed critically in order to select the best experiences available. The aim was to access the literature and the data available about the smartphones' use in health promotionfield. Health promotion is the process of enabling people to increase control over, and to improve,their health. It moves beyond a focus on individual behavior towards a wide range of social andenvironmental interventions [15]. The Bibliographic details for each item from the initial search were reviewed independently by members of the project team. Articles were retrieved for further analysis according to the following criteria:

- The full text of the article is readily and freely available online, i.e. open access or available via the host institution's e-library of online journals.

- The article is published in English or German.

- The article includes a explicit reference of use of smartphones for health promotion topics.

- All the three reviewers agree that the article should be included (disagreements over which items according to these criteria, the articles were selected by title, abstracts and then full-text. Our search has also some limitations, described in the discussion section that must be considered when interpreting the results.

\section{Results}

Published studies included comparative research studies, reliability studies and cross sectional design studies of the effectiveness of smartphone apps to estimate range of motion in elbow and knee joint. Globally, the initial search using the above mentioned keywords returned 4669 items. After theremoval of duplicates and titles and abstracts revision, the reviewers agreed that 63 articles were deserving of a closer examination, as strictly related to the topic of interest. Among these, 32 wereidentified as meeting the inclusion criteria and specifically centered on these were subjected to further analysis [16]. The correlation between knee flexion ROM that measured by smart phone application and that measured by digital goniometer in the study group was strong positive significant correlation $(r=0.88$, $p=0.0001)$. 
Table (1): Descriptive statistics of ROM measured by smart phone application.

\begin{tabular}{lllll}
\hline & $\mathrm{X} \pm \mathrm{SD}$ & \multicolumn{3}{c}{ Minimum Maximum Range } \\
\hline Knee flexion & $53.42 \pm 5.11$ & 43.5 & 68.4 & 24.9 \\
Knee extension & $178.16 \pm 1.56$ & 173 & 180 & 7 \\
Elbow flexion & $40.21 \pm 3$ & 32.5 & 47 & 14.5 \\
Elbow extension & $178.28 \pm 1.61$ & 174 & 180 & 6 \\
\hline
\end{tabular}

X: Mean.

SD: Standard Deviation.

The correlation between knee extension ROM that measured by smart phone application and that measured by digital goniometer in the study group was weak negative non-significant correlation ( $r=$ $-0.02, p=0.74)$. The correlation between elbow flexion ROM that measured by smart phone application and that measured by digital goniometer in the study group was strong positive significant correlation ( $r=0.95, p=0.0001$ ). The correlation between elbow extension ROM that measured by smart phone application and that measured by digital goniometer in the study group was weak negative non-significant correlation ( $r=-0.06, p=$ 0.42 ). The correlation between 1 st and 2 nd knee flexion ROM measurements that measured by smart phone application in the study group was strong positive significant correlation $(r=0.82, p=0.0001)$. The correlation between 1 and 2 nd knee extension ROM measurements that measured by smart phone application in the study group was strong positive significant correlation ( $r=0.8, p=0.0001)$. The correlation between 1 and 2 nd elbow flexion ROM measurements that measured by smart phone application in the study group was strong positive significant correlation ( $r=0.91, p=0.0001)$. The correlation between 1 st and 2 nd elbow extension ROM measurements that measured by smart phone application in the study group was strong positive significant correlation ( $r=0.81, p=0.0001)$.

\section{A comparative research studies:}

Yaikwawongs et al., (2009) compared the reliability of ROM in the knee joint in two techniques including digital compass goniometer and roentgenographic picture. ICC was calculated 0.973 [17] Jenny et al., (2013) compared the reliability of mesuring by smartphone and standard routine method measurements of flexion range of knee joint in 10 patients with TKA. The measurements were performed six times for each method (i.e., totally 12 times). They showed that the smartphone usage after TKA was one of the most reliable ways of measuring [5]. Ferriero et al., (2013) compared the DrG software on the smartphone with the conventional photographic-based goniometry in 35 subjects. According to results, intra-rater and inter-rater correlations were always calculated more than 0.958 in this study. The results showed that Dr G software was a re-liable method to measure the ROM of knee and are much easier than the conventional method [6]. According to the recent study, Charlton et al., (2014) evaluated the reliability of smartphone to measure the flexion, rotation, abduction and adduction movement of the hip joint. This study was conducted on 20 healthy young men. The final results showed that the smartphone had good to excellent reliability for most of the movements but it had moderate to good reliability on abduction, adduction and external rotation [17]. In other study, Ockendon et al., (2012) repeated this study and the validity of smartphone versus knee goniometer was estimated for five healthy volunteers. The intra-observer correlation was 0.982 for the smartphone [4] . Cleffken et al., (2007) compared two methods of digital goniometry and electronic digital inclinometer (EDI 320) in 42 healthy subjects. They showed that active maximum flexion had lower excursions than passive maximum flexion. In addition, passive maximum flexion showed higher levels of reproducibility [18]. Photograph-based applications, whereby clinicians make measurements in a delayed fashion (postproduction and independent of the patient's location), allow images to be printed and filed in patient notes for comparison during subsequent visits. Like inclinometry based apps, photograph-based applications allow ac-curate ROM assessment when a goniometer is not available or when a face-toface interaction with a health professional is not immediately available. Moreover, the physicianpatient interaction can potentially be enhanced by demonstrating the patient's progress in ROM over time [5]. This study is the first to compare 4 different shoulder ROM assessment tools in a pathologic patient cohort. The 4 assessment modalities used (the clinician's visual estimation, inclinometerbased smartphone application [GetMyROM], photograph-based [DrGoniometer] smartphone application, and UG) demonstrated ex-cellent agreement. This finding was similar to that of Werner et al., who assessed postsurgical shoulder ROM in patients having undergone total shoulder replacement surgery and reported excellent correlation when using an inclinometer Smartphone application in isolation [19]. This study is also one of the few studies that assessed an older population cohort (mean age, 46 years), in various planes of shoulder movement, with various shoulder diseases and diagnoses. The only other study to examine inclinometer-and photograph-based shoulder assessment tools relied exclusively on measurements of external rotation performed on young, healthy subjects (mean age, 26.4 \pm 7.6 years) [20]. 


\section{Reliability studies:}

Recent studies have shown that other smartphone apps can provide valid, reliable measurement of motion at a specific joint or region, such as the ankle, knee, wrist, or spine [21].

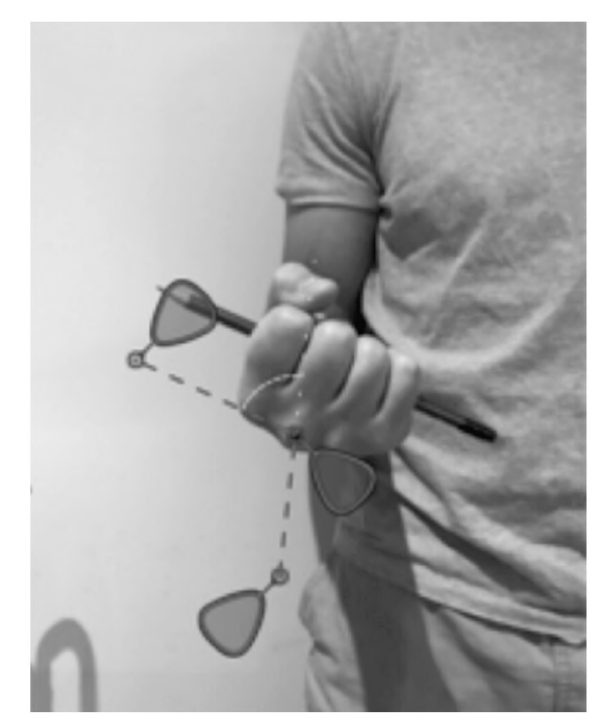

Fig. (1): Participant positioning for measurement of supination range of motion.

These studies showed that smartphone range of motion measurement applications have good validity and reliability in measuring range of motion in different joints (elbow, knee, and fifth metatarsophalangeal joints [4]. The smartphone measurements of intrarater reliability in the present study were higher than those reported by [22] but lower than the value reported by [23] when they compared the smartphone-based application developed for photographic-based goniometry, Dr. Goniometer, and the Universal goniometer on the elbow joint. The smartphone application has advantages for novice practitioners and students and could potentially be used by patients to measure and monitor their own progress because it requires less knowledge of surface anatomy landmarks, less palpation skill, and less [2]. A Smartphone image-based application showed an inter class correlation coefficient between 0.96 and 0.99 for intra and interrater reliability, respectively, and was shown to be a reliable and useful alternative tool for elbow joint goniometry [23]. The use of smartphone as a digital inclinometer has significant benefits, such as availability, appreciable cost of inclinometer applications; and easy measurement due to the commercial band which fixes the device in considered places. So during the examinations, examiners do not need both hands, and also it enables the patients to evaluate their process of healing and the efficacy of treatment by themselves at home [24]. Dr. G can provide an alternative or an additional method of measurement, useful for different needs in many different clinical settings (e.g. follow-up after treatment, assessment of intraoperative joint mobility, for medico legal purposes). Moreover, the images of the measurement can be included in the patient's medical record as evidence of the quality of care provided [5]. Dr. Goniometer was shown to be a valid alternate tool for measuring forearm supination when compared with the universal goniometer [25].

\section{Discussion}

The results of this review indicate that smartphone apps can be efficacious in estimating range of motion and in pediatric]. Participants prefer apps that coach and motivate them and provide tailored feedback toward personally set goals. Smartphone apps are preferred over use of a computer general guidelines have been offered for interpreting ICC values, 0.50 represents poor reliability, 0.50-0.75 represents moderate reliability, and 0.75 represents good reliability [26]. 'Acceptable reliability' must be decided by the clinician using the specific test or measure [27]. It is important to provide readers with sufficient information regarding the measurement/rating process, because reliability and agreement estimates may vary according to the time interval between repeated measurements; the general conditions underlying the measurement situation (e.g., atmosphere, location); the specific measurement setting (e.g., imaging modalities, light); or the complexity of the measurement/rating process or characteristics of the rated subjects themselves [28]. As an example [29] stated "A k-value between 0.00 and 0.20 was classified as "slight"; between 0.21 and 0.40 as "fair"; between 0.41 and 0.60 as "moderate"; between 0.61 and 0.80 as "substantial"; and between 0.81 and 1.00 as "almost perfect", nevertheless, these 'labels' do not indicate the practical or clinical relevance of results. To achieve more reliable measurements in clinical settings, practice and discussion of measurement guidelines should be used as a natural part of the introduction of colleagues and as a way to create consensus among more experienced hand therapists [30]. The literature suggests that smartphone-based applications have the capacity to be valid when measuring range of motion; however, for a measurement instrument to be valid, it must first be reliable [31] used the iPhone Dr. Goniometer application to examine elbow range of motion and reported good intrarater and interrater reliability interclass correlation coefficients $=.99$ ). Of the 3 lower-extremity studies using the Dr. Goniometer app to examine reliability [20]. Dr Goniometer and 
the universal goniometer demonstrated good-toexcellent intrarater and inter-rater reliability in both the fractured forearm and healthy forearm group, an exception existed in the healthy forearm group, where both Dr. Goniometer and the universal goniometer demonstrated poor inter-rater reliability (interclass correlation coefficients, 0.34 and 0.42 , respectively) [23]. This study was also designed such that it reflected the full clinical use of the applications by requiring the assessor to both photograph the joint and align the application is measurement point, this overcame the limitations of a previous Dr. Goniometer study that did not require the assessors to take the photographs and only required the assessors to measure a set of 28 preprepared images [25]. Dr. Goniometer was shown to be a valid alternate tool for measuring forearm supination when compared with the universal goniometer [23]. Wenzlaff et al., reported intrarater reliabilities that ranged from .95 to .99 for knee flexion and from .85 to .97 for knee extension. Interrater reliability, while generally high, can be variable based on the joint motion being examined and the type of device and application used [25] The Smartphone application has demonstrated adequate reliability and validity to support its potential use to assess passive hip joint range of motion both clinically and for large-scale screening if a bubble inclinometer or 3DMA system is not available [32]. A Smartphone application provides a reliable and valid method of assessing passive hip joint range of motion in young active males [6]. A software programme was shown to be more reliable than the universal goniometer when measuring maximal range of motion of the knee [33] Further a Smartphone-based application, showed an interclass correlation coefficients for intra and inter-rater reliability higher than 0.956 [5]. Elbow angle measured with a universal goniometer was compared with digital photographs. The photography-based method showed interclass correlation coefficients between 0.96 and 0.98 for its validity, and better inters-observer reliability than the universal goniometer [34]. A Smartphone image-based application showed an interclass correlation coefficients between 0.96 and 0.99 for intra-and interrater reliability, respectively, and was shown to be a reliable and useful alternative tool for elbow joint goniometry [23]. One of the clear benefits of Smartphone photography-based goniometry over other devices is that it represents a portable tool accessible to all. Its non-invasive nature and its cost-effectiveness for investigators and clinicians make it a practical tool to assist with evauation and treatment compliance [35]. Dr. Goniometer application potentially offers a superior method of measurement over SG as visualizing the landmarks may be simplified in a two-dimensional plane and provides a record of the image and measurement [20]. Anderson et al., (2013) investigated an inclinometer-based iPhone application to measure interrater and intra-rater reliability and concurrent validity of shoulder flexion range of motion in two ranges: (1) Less than 90 degrees and (2) More than 90 degrees. The authors reported intra-rater reliability of 0.92-0.99 for the application and 0.860.98 for the SG with two raters; inter-rater reliability was reported between 0.84 and 0.91 for the application and 0.63-0.88 for the SG and concurrent validity between 0.67 and 0.94 [36].

\section{References}

1- GARCÍA-RUBIO J., PINO J., OLIVARES P. and IBÁÑEZ S.: "Validity and Reliability of the WIMUTM Inertial Device for the Assessment of Joint Angulations". International Journal of Environmental Research and Public Health, 17 (1): 193, 2019.

2- ALAWNA M., UNVER B. and YUKSEL E.: "The Reliability of a Smartphone Goniometer Application Compared With a Traditional Goniometer for Measuring Ankle Joint Range of Motion". Journal of the American Podiatric Medical Association, 109 (1): 22-9, 2019.

3- KEOGH J., COX A., ANDERSON S., LIEW B., OLSEN A., SCHRAM B. and FURNESS J.: "Reliability and validity of clinically accessible smartphone applications to measure joint range of motion: A systematic review". PLOS ONE: 14 (5): 22-31, 2019.

4- OCKENDON M. and GILBERT R.E.: "Validation of a novel smartphone accelerometer-based knee goniometer". J. Knee Surg., 25: 341-45, 2012.

5- FERRIERO G., VERCELLI S., SARTORIO F., MUNOZLASA S., ILIEVA E., BRIGATTI E., et al.: "Reliability of a smartphone-based goniometer for knee joint goniometry". Int. J. Rehabil. Res., 36: 146-51, 2013.

6- CHARLTON P., MENTIPLAY B., PUA Y. and CLARK R.: "Reliability and concurrent validity of a Smartphone, bubble inclinometer and motion analysis system for measurement of hip joint range of motion". Journal of Science and Medicine in Sport, 18 (3): 262-7, 2015.

7- HANSSON G.Å., BALOGH I., OHLSSON K. and SKERFVING S.: "Measurement of wrist and forearm positions and movements: effect of, and compensation for, goniometer crosstalk". J. Electromyogr. Kinesiol., 14 (3): 35567, 2004.

8- JUUL-KRISTENSEN B., HANSSON G.Å., FALLENTIN N., ANDERSEN J.H. and EKDAHL C.: "Assessment of work postures and movements using a video-based observation method and direct technical measurements". Appl. Ergon., 32 (5): 517-24, 2001.

9- SVENSSON M., LIND V. and LÖFGREN-HARRINGE M.: "Measurement of knee joint range of motion with a digital goniometer: A reliability study". Physiotherapy Research International, 24 (2): 1765, 2019. 
10- VERCELLI S., SARTORIO F., BRAVINI E. and FERRIERO G.: "DrGoniometer: A reliable smartphone app for joint angle measurement". British Journal of Sports Medicine, 51 (23): 1703-4, 2016.

11- BENDER J.L., YUE R.Y., TO M.J., DEACKEN L. and JADAD A.R.: "A lot of action, but not in the right direction: Systematic review and content analysis of smartphone applications for the prevention, detection, andmanagement of cancer. J. Med. Internet Res., 15 (12): 287, 2013.

12-BORT-ROIG J., GILSON N.D., PUIG-RIBERA A., CONTRERAS R.S., TROST S.G., et al.: "Measuring and influencingphysical activity with smarphone technology: A systematic review". Sports Med., 44 (5): 671-86, 2014.

13-STEPHENS J. and ALLEN J.: "Mobile phone interventions to increase physical activity and reduce weight: Asystematic review". J. Cardiovasc. Nurs., 28 (4): 320-29, 2013.

14- OZDALGA E., OZDALGA A. and AHUJA N.: "The smartphone in medicine: A review of current and potential use among physicians and students". J. Med. Internet Res., 14 (5): 128, 2012.

15- World Health Organization: "Health topics: Health promotion". Available from: http://www.who.int/topics/ health_promotion/en/, 2013.

16- HANDEL M.J.: "Health (mobile health) using Apps for health and wellness". Explore (NY), 7 (4): 256-61, 2011.

17- JENNY J.Y.: "Measurement of the knee flexion angle with a Smartphone-application is precise and accurate". J. Arthroplasty, 28 (5): 784-7, 2013.

18- CLEFFKEN B., VAN BREUKELEN G., BRINK P., VAN MAMEREN H. and OLDEDAMINK S.: "Digital goniometric measurement of knee joint motion. Evaluation of usefulness for research settings and clinical practice". Knee, 14 (5): 385-9, 2007.

19- WERNER B.C., HOLZGREFE R.E., GRIFFIN J.W., LYONS M.L., COSGROVE C.T., HART J.M., et al.: "Validation of an innovative method of shoulder rangeof-motion measurement using a smartphone clinometer application". J. Shoulder Elbow Surg., 23: 275-82, 2014.

20- MITCHELL K., GUTIERREZ S.B., SUTTON S., MORTON S. and MORGENTHALER A.: "Reliability and validity of goniometric iPhone applications for the assessment of active shoulder external rotation". Physiother. Theory Pract., 30: 521-5, 2014.

21- FURNESS J., SCHRAM B., COX A.J., ANDERSON S.L. and KEOGH J.: "Reliability and concurrent validity of the iPhone? Compass application to measure thoracic rotation range of motion (ROM) in healthy participants". Peer. J.; 6: 4431, 2018.

22- OTTER S.J., AGALLIU B., BAER N., et al.: "The reliability of a smartphone goniometer application compared with a traditional goniometer for measuring first metatarsophalangeal joint dorsiflexion". J. Foot Ankle Res., 8: 30, 2015.

23- FERRIERO G., SARTORIO F., FOTI C., PRIMAVERA D., BRIGATTI E. and VERCELLI S.: "Reliability of a new application for smartphones (DrGoniometer) for elbow angle measurement". PM R, 3: 1153-4, 2011.
24- SHIN S.H., RO DU H., LEE O.S., OH J.H. and KIM S.H.: "Within-day reliability of shoulder range of motion measurement with a smartphone". Man. Ther., 17 (4): 298-304, 2012.

25- REID S. and EGAN B.: "The validity and reliability of DrGoniometer, a smartphone application, for measuring forearm supination". Journal of Hand Therapy, 32 (1): 110-7, 2019.

26- PORTNEY L.G. and WATKINS M.P.: "Foundations of Clinical Research: Applications to Practice. Upper Saddle River, N.J.: Pearson Prentice Hall, 2009.

27- VAN GENDEREN F., De BIE R., HELDERS P. and VAN MEETEREN N.: "Reliability research: Towards a more clinically relevant approach. Phys. Ther. Rev., 8: 16976, 2003.

28- De VET H.C.W., TERWEE C.B., KNOL D.L. and BOUTER L.M.: "When to use agreement versus reliability measures". Journal of Clinical Epidemiology, 59 (10): 1033-9, 2006.

29- ZEGERS M., De BRUIJNE M.C., WAGNER C., GROENEWEGEN P.P., VAN DER WAL G. and De VET H.C.: "The inter-rater agreement of retrospective assessments of adverse events does not improve with two reviewers per patient record". Journal of Clinical Epidemiology, 63 (1): 94-101, 2010.

30- STOCHKENDAHL M.J., CHRISTENSEN H.W., HARTVIGSEN J., VACH W., HAAS M., HESTBAEK L., et al.: "Manual examination of the spine: A systematic critical literature review of reproducibility". Journal of Manipulative and Physiological Therapeutics, 29 (6): 475-85, 2006.

31- ENGSTRAND C., KREVERS B. and KVIST J.: "Interrater Reliability in Finger Joint Goniometer Measurement in Dupuytren's Disease". American Journal of Occupational Therapy, 66 (1): 98-103, 2011.

32- WENZLAFF J. and TRUXTON T.: "Berry D., Brooks E. Intra-and intertester reliability of the Dr. Goniometer iPhone/iPad app at the knee joint". J. Athl. Train., 49: $243,2014$.

33- VERHAEGEN F., GANSEMAN Y., ARNOUT N., VANDENNEUCKER H. and BELLEMANS J.: "Are clinical photographs appropriate to determine the maximal range of motion of the knee?". Acta Orthop. Belg., 76: 794-8, 2010.

34- BLONNA D., ZARKADAS P.C., FITZSIMMONS J.S and O'DRISCOLL S.W.: "Validation of aphotographybased goniometry method for measuring joint range of motion". J. Shoulder Elbow Surg., 21 (1): 29-35, 2012.

35- CUESTA-VARGAS A.I. and ROLDÁN-JIMÉNEZ C.: "Validity and reliability of arm abduction angle measured on smartphone: A cross-sectional study". BMC Musculoskelet. Disord., 17: 1-8, 2016.

36- ANDERSON D., ENGLISH E., VAREE K., DIAZ D. and LOWE D.: "Reliability and validity of an iPhone inclinometer as compared to a universal goniometer as a tool for measuring joint motion of the shoulder in apparently healthy subjects". Orthopaedic Physical Therapy Practice, 25: 34-8, 2013. 


\section{حول إستخدامات برنامج الهواتف الذكية

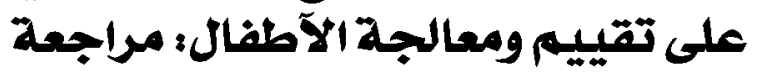

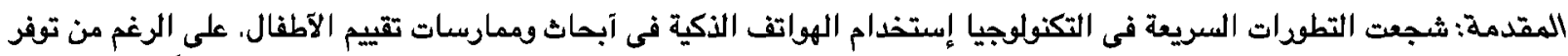

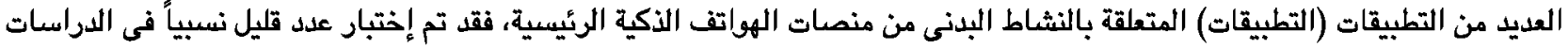
البحثية لتحديد فعاليتها في تقييم قوة الآطفال وقوة العضلات.

الطرق : فى هذه المقالة، نلخص البيانات حل إستخدام تطبيقات الهواتف الذكية لتقدير نطاق الحركة إستاداً إلى عمليات البحث البيليوغرافية

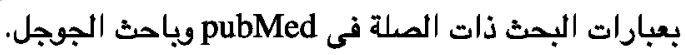

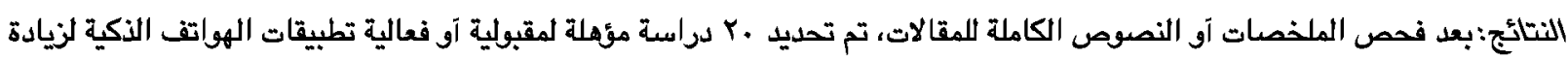

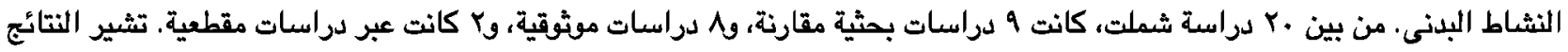

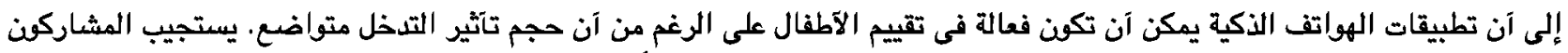

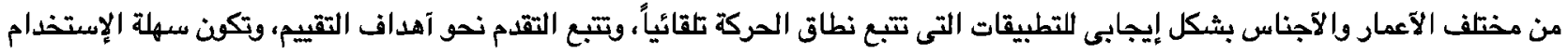
ومرنة بما يكفى للإستخدام مع عدة آنواع من نطاق إنماب الصركة.

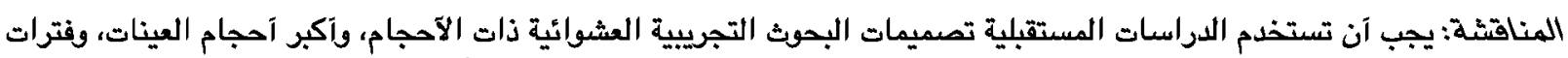

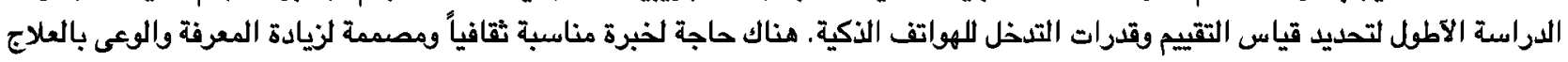

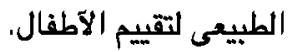

الإستتاجات: في الختام، يمكن إستخدام تطبيق الدكتو جونيومتر للهواتف الذكية في الممارسة السريرية والبحث كبديل سهل ومريح

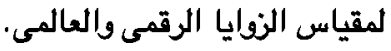

